\title{
Estimating the 'Value at Risk' of EUA futures prices based on the Extreme Value Theory
}

\author{
Zhi-Fu Mi ${ }^{\mathrm{a}, \mathrm{b}}$, Yue-Jun Zhang ${ }^{\mathrm{a}, \mathrm{b}}$ \\ ${ }^{a}$ School of Management and Economics, Beijing Institute of Technology, Beijing 100081, China \\ ${ }^{b}$ Center for Energy and Environmental Policy Research, Beijing Institute of Technology, Beijing \\ 100081, China
}

\begin{abstract}
This paper employs the Extreme Value Theory (EVT) to measure the 'Value at Risk' (VaR) of EUA futures prices. The results show that during the sample period, first, the EVT approach can be used to reliably measure the extreme risk of carbon futures markets of the EU ETS, both for Phase I and Phase II. Second, the downside extreme risk of carbon futures market outweighs the upside risk, with evident asymmetric features. Moreover, the average VaR of carbon futures contract DEC10 proves much less than that of contract DEC07 during the sample period.
\end{abstract}

Key words: EU ETS, Extreme Value Theory (EVT), Value at Risk (VaR), Carbon Market

\section{Introduction}

The European Union Emissions Trading Scheme (EU ETS) was put into operation on January 1, 2005 by the European Commission (EC) to foster early compliance with the greenhouse gas emissions reduction targets defined in the Kyoto Protocol (Zhang and Wei, 2010a). Up to now, the EU ETS has developed fast. In the first year of operation, the total value was only \$7.9 billion. However, after five consecutive years of robust growth, the total value of the EU ETS grew to $\$ 119.8$ billion in 2010. The European Union Allowances (EUAs) market accounted for 84 percent of global carbon market value in 2010, whose dominance became more pronounced in the carbon market all over the world than ever (Linacre et al., 2011).

With the trading value growth of the EU ETS these years, more and more financial intermediaries participate in the carbon trading under the EU ETS; as a result, EUAs trading has turned out to be a new choice for investors to make profits and disperse asset risks and carbon market conditions become increasingly complex. And according to the survey by World Bank, despite well-documented short-term uncertainty surrounding the carbon market, respondents are optimistic about the possibility of a binding agreement in the longer term (Linacre et al., 2011). So 
carbon trading markets may receive continuous interests in the near future years and in order to resist trading risk and reduce investing loss, it is of vital importance for carbon market investors to measure the extreme market risk of the EU ETS properly. On the other hand, for hedgers who need the EUAs to offset their allowance shortages, the extreme price risk carbon trading will influence their confidence and thus affect their outcome of emissions reduction (Wei et al., 2010).

As for current literature about carbon market risk, there are several types as follows. First, some literature researches the risk shock of the carbon market to energy sectors (such as power sector and wind energy). Daskalakis and Markellos (2009) justify that electricity risk premia are affected by emission allowance prices on the basis of carbon market uncertainties and of trading strategies adopted by electricity producers who may exploit their initial allocation of free EUAs. Oberndorfer (2009) explores the relation between carbon market and stock market by means of the panel GARCH approach, arguing that carbon price change is positively related to the stock returns of the most important European electricity corporations. Furthermore, carbon price appreciation and depreciation do not have any asymmetric relation with the change of stock returns. Therefore, it is apparent that the EU ETS has an important impact on the financial markets and the value of the corporations covered. Blanco and Rodrigues (2008) examine the effect of the EU ETS on energy investment. The results show that the low price of CERs and ERUs on the EU ETS market can play a negative role on wind energy, and a minimum price of around 40 euros per ton of $\mathrm{CO}_{2}$ should be attained to maintain present support levels for wind.

Second, some literature investigates the risk of the outside environment (such as macroeconomic conditions, environmental policy uncertainty, R\&D investment and energy prices) to carbon markets. Alberola et al. (2008a) is the first to empirically study the expected impact of industrial production variation in the EU ETS sectors on carbon price changes. Their results show that during 2005-2007, only three among nine industrial sectors have significant effect on $\mathrm{CO}_{2}$ permit price, i.e., the combustion, paper and iron sectors. Chevallier (2009) examines the empirical influence of macroeconomic risk factors on carbon futures. The results document that carbon futures returns may be weakly forecast on the basis of two variables from the stock and bond markets. Chevallier et al. (2009) evaluate the impact of the 2006 compliance event on changes in investors' risk aversion on the European carbon markets. Their results show evidence of a dramatic change in the market perception of risk around the 2006 yearly compliance event. 
Blyth et al. (2009) provide an intuitive understanding of the key dynamics and risk factors in carbon markets. The results indicate that support for early stage R\&D may reduce both total abatement cost and carbon price risk. Zhang and Wei (2010b) explore the complex impact of fossil fuel markets (oil, natural gas and coal) on carbon markets, using some econometrical methods including the state space model, VAR model etc. And they find that significant time-varying cointegration exists between fossil fuel prices and carbon prices. Pinho and Madaleno (2011) examine interactions between carbon, electricity and fossil fuel (coal, oil and natural gas) returns using the Vector Error Autoregressive Correction Model (VECM). Results reveal that nuclear power generation can limit increases in prices of electricity and that the effect of carbon depends on the energy mix and electricity deregulation stage of the country under analysis. It seems that in European Energy Exchange (EEX) more carbon coercion is undergone and innovations in carbon are stronger in electricity prices. Blyth and Bunn (2011) utilizes a stochastic simulation model to analyze the key drivers of carbon price risk in the EU ETS. The results indicate that policy risks tend to dominate when carbon prices are low, whereas market risks tend to dominate when carbon prices are high.

Furthermore, with the growing trading data of the EU ETS, some literature has appeared on the pricing mechanism of the carbon market from financial perspectives, especially its price dynamics. Reilly and Paltsev (2007) display the complex reasons for carbon price dynamics. They simulate the carbon market under the EU ETS, in particular the volatility of carbon price, and find that the carbon price should have ranged between 0.6 and 0.9 euros per ton of $\mathrm{CO}_{2}$ during 2005-2007, obviously differing from the real price in 2005, i.e., 20-25 euros per ton of $\mathrm{CO}_{2}$. Subsequently, they analyze several possible reasons for this discrepancy; for example, besides the shortcomings in the model's hypotheses and specification, the natural gas price is too high; the scarcity of both hydro power and nuclear power spur the rate increase of coal-fired power; the fundamental conditions of member states have not prepared well enough, such that the trading volume of the carbon market seems relatively limited. Alberola et al. (2008b) show evidence that the EU ETS carbon price change over 2005-2007 followed two structural breaks; one occurring in April 2006, mainly for the verified carbon emissions data of 2005 disclosed by the EC; the other in October 2006, as a consequence of the EC's announcements regarding the restriction of the 2008-2012 allowance allocation. From the price breaks, we can see the influence of institutional 
and market events on carbon price change. Zhang and Wei (2011) introduce the mean reversion theory to verify the existence of mean reversion phenomenon in carbon market under the EU ETS. Main empirical results indicate that whether before the compliance break in 2006 or after that, no one of carbon market prices, returns, volatility and risk moves along a mean reversion process; in other words, their movements take on some divergence, without significant evidence to be predictable. Feng et al. (2011) examine the carbon price volatility using data of the EU ETS from a nonlinear dynamics point of view. The results show that first, carbon price is not a random walk process and proves mildly chaotic; second, carbon price fluctuation is influenced not only by the internal market mechanism, but also by the heterogeneous environment.

To the best of our knowledge, however, there is little literature to measure the extreme risk of carbon markets from the perspective of its price dynamics. As a newly developing market, carbon market is affected not only by the market mechanism itself, but also by the outside uncertain environment particularly in the short run. For example, carbon market fluctuation is affected by international political conditions (such as the climate negotiation dynamics), energy price changes, unusual temperature and emissions allowance allocation (such as NAPs) solution disclosure etc, which result in extreme risk of carbon markets (Alberola et al., 2008b; Alberola and Chevallier, 2009; Chevallier et al., 2009). Therefore, it is quite possible that extreme values might appear in carbon markets, and some traditional methods for risk measurement may produce biased results.

The Extreme Value Theory (EVT) has been applied in many fields where extreme values may appear. Such fields range from hydrology (Katz et al., 2002), insurance (McNeil, 1997), finance (Danielsson and de Vries, 1997; Gilli and Kellezi, 2006) to oil markets (Marimoutou et al., 2009). EVT provides a solid framework to formally study the behavior of extreme observations. Unlike other models which usually focus on the whole distribution, EVT approach concentrates on the tail of a distribution rather than the entire distribution, and has been found to be a convenient framework for the separate treatment of the tails of a distribution which allows for asymmetry. So it could potentially perform better than other approaches in terms of measuring unexpected extreme changes (Longin, 2000; Marimoutou et al., 2009). Therefore, this paper introduces the EVT to measure carbon market risk (Value at Risk, VaR), and compares the results with the traditional VaR approaches, such as the Variance-Covariance and Monte Carlo approaches. Here, the Variance-Covariance approach incorporates the GED-GARCH models, and more details of 
VaR estimates based on the GED-GARCH models can be found from Fan et al. (2008).

Additionally, carbon emissions permit has been regarded as a commodity, so there are different meanings of carbon prices risk for different market participants. If carbon prices rise, the carbon emissions allowance sellers will get profits while the buyers will incur losses. On the other hand, if carbon prices fall, the emissions allowance buyers will obtain returns while the sellers will face losses. Therefore, both the downside and upside market risks should be estimated as for the carbon market risks. For this purpose, we will shed light upon two issues in this paper. First, we introduce the EVT to estimate the carbon market risks. Second, we analyze the VaRs of the Phase I and Phase II of the EU ETS in term of downside and upside risks, in order to foster a comprehensive understanding of carbon market risks.

The rest of the paper is organized as follows. Section 2 gives the methodology of the Extreme Value Theory and the Value at Risk. Section 3 presents the data and empirical results and discussions, while Section 4 provides some concluding remarks.

\section{Methodologies}

Suppose $C_{t}$ is the EUA futures price on day $t$, then the carbon price return on day $t$ is defined as

$$
R_{t}=100\left(\ln C_{t}-\ln C_{t-1}\right) .
$$

If the distribution function of return series $\left\{R_{t}\right\}$ is defined as

$$
F(r)=\operatorname{Pr}\left\{R_{t} \leq r\right\},
$$

then given a high threshold $u$, the distribution of excess values of $R$ over threshold $u$ is defined as

$$
F_{u}(y)=\operatorname{Pr}\{R-u \leq y \mid R>u\}=\frac{F(y+u)-F(u)}{1-F(u)}, y>0
$$

which represents the probability that the value of $R$ exceeds the threshold $u$ by at most an amount y. As described by Balkema and de Haan (1974) and Pickands (1975), for sufficiently high threshold $u$, the distribution function of the excess $\left(F_{u}(y)\right)$ may be approximated by the Generalized Pareto Distribution (GPD), which is 


$$
G(y)=\left\{\begin{array}{ll}
1-\left(1+\xi \frac{y}{\beta}\right)^{-1 / \xi} & \text { if } \xi \neq 0 \\
1-e^{-y / \beta} & \text { if } \xi=0
\end{array},\right.
$$

where $y \geq 0$ when $\xi \geq 0$ and $0<y<-\beta / \xi$ when $\xi<0 . \xi$ is the shape parameter and $\beta>0$ is the scale parameter. Therefore, for a large threshold $u$, we can estimate $F_{u}(y)$ by $G(y)$. By setting $r=y+u$, the tail estimate can be obtained based on Eqs. (3) and (4) as follows:

$$
F(r)=(1-F(u)) G(y)+F(u) .
$$

The function $F(u)$ can be estimated non-parametrically using the empirical cumulative distribution function (CDF):

$$
F(u)=\frac{n-N}{n},
$$

where $n$ is the sample size and $N$ is the number of exceedances. After substituting Eqs. (4) and (6) into Eq. (5), we get the following estimate for $F(r)$ :

$$
\overline{F(r)}=1-\frac{N}{n}\left(1+\bar{\xi} \frac{r-u}{\bar{\beta}}\right)^{-1 / \bar{\xi}} .
$$

where $\bar{\xi}$ and $\bar{\beta}$ are estimates of $\xi$ and $\beta$ respectively, which can be obtained by the maximum likelihood estimation (MLE) based on the Eq. (4)

For a given confidence level $p>F(u)$, VaR is the $p$ th quantile of the distribution $F$. So the VaR can be obtained from Eq. (7) by solving for $r$ as follows:

$$
\operatorname{VaR}=u+\frac{\bar{\beta}}{\bar{\xi}}\left(\left(\frac{n}{N}(1-p)\right)^{-\bar{\xi}}-1\right) .
$$

It should be noted that the threshold $u$ is determined by the sample mean excess function (MEF), which is defined as

$$
e(u)=\frac{\sum_{t=1}^{n}\left(R_{t}-u\right)}{\sum_{t=1}^{n} 1_{\left\{R_{t}>u\right\}}},
$$

where $1_{\{*\}}$ is an indicator function. The MEF is the sum of the excesses over the threshold $u$ divided by the number of data points which exceed the threshold $u$ and describes the expected overshoot of a threshold once an exceedance occurs. If the empirical MEF is a positively sloped 
straight line above a certain threshold $u$, it is an indication that the data follows the GPD with a positive shape parameter $\xi$ (Marimoutou et al., 2009).

Ultimately, we introduce the method to test the reliability of VaR results. According to the methods presented in Kupiec (1995), suppose $p$ is the confidence level of VaR, $n$ is the sample size, $N$ is the failure days, $f=N / n$ is the failure rate and $1-p$ is the expected value of the failure rate. Then according to the likelihood ratio (LR) proposed by Kupiec (see Eq. (10)), we test the null hypothesis $H_{0}: 1-p=f$, i.e., whether the failure rate of VaR equals $1-p$ or not.

$$
L R=-2 \ln \left[p^{n-N}(1-p)^{N}\right]+2 \ln \left[(1-f)^{n-N} f^{N}\right] .
$$

Under the condition of the null hypothesis, the statistic LR subjects to the $\chi^{2}$ distribution with one degree of freedom, whose critical value of $95 \%$ confidence level is 3.84. If $L R>3.84$, the null hypothesis is rejected, i.e., the model of estimating VaR is not reliable; otherwise, the results of VaR may be acceptable.

\section{Empirical result analysis}

\subsection{Data definitions}

This paper aims to measure the extreme risk of carbon futures market in European Climate Exchange (ECX) in terms of the two phases of the EU ETS (2005-2007 for Phase I and 2008-2012 for Phase II). Given that almost all the carbon futures contracts have highly consistent price trends in the same phase, we select one contract price as the representative for the two phases respectively. Specifically, we select the price of contract DEC07 of ECX expired on December 17 of 2007 as the representative of Phase I, and the price of contract DEC10 expired on December 20 of 2010 as the representative of Phase II. The sample periods range from 2005/4/22 to 2007/12/17 for Phase I and from 2008/1/2 to 2010/12/20 for Phase II, with 682 and 754 observations respectively (see Figure 1). It should be noted that the carbon futures price is quoted in euros per tonne of EU allowances. 


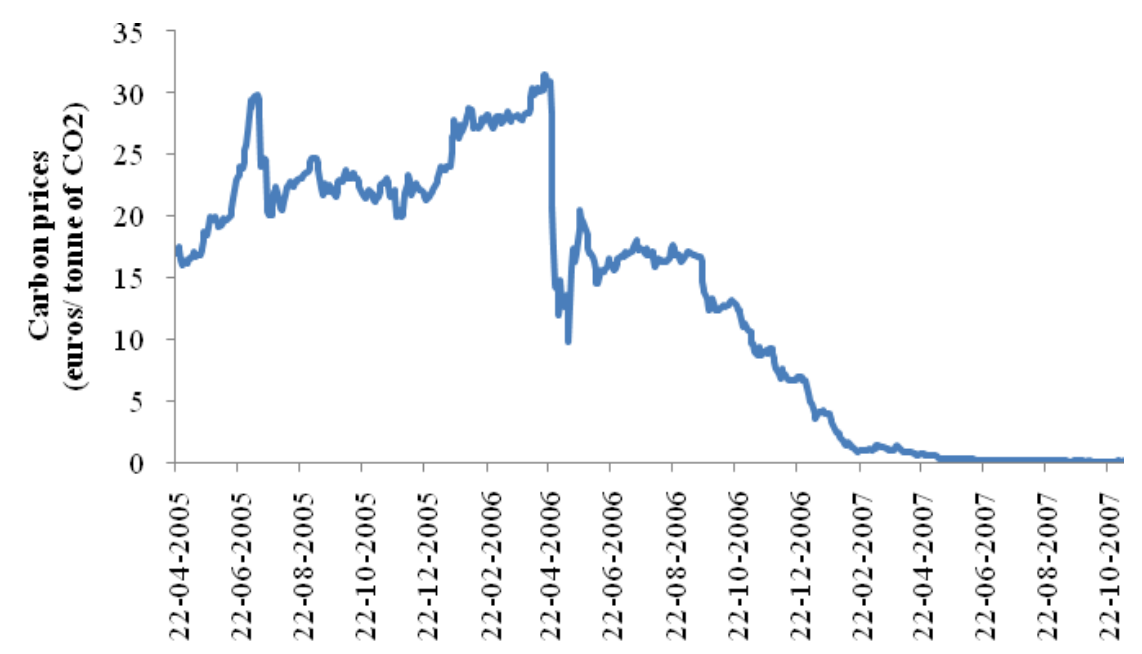

(a) Prices of carb on futures contract DEC0 $7: 2005 / 4 / 22-2007 / 12 / 17$

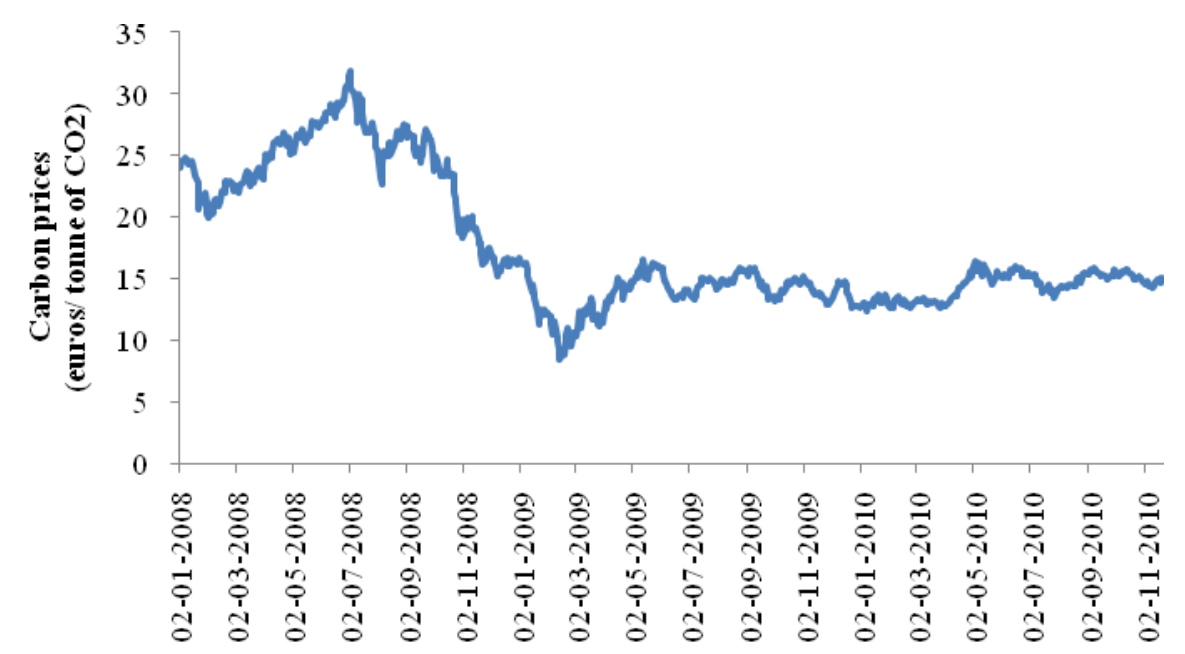

(b) Prices of carb on futures contract DEC10: 2008/1/2 - 2010/12/20

Fig. 1. Carbon futures prices of the ECX

\subsection{Summary statistics of carbon price returns}

The basic statistics of price returns of contract DEC07 and DEC10 are shown in Table 1. We find that the standard deviation of contract DEC07 appears evidently larger than that of contract DEC10, which reflects the sharper volatility of carbon price in Phase I. Additionally, as implied by the JB statistics, neither of the carbon prices in Phase I and Phase II follows the Normal distribution, which corroborates the results by Paolella and Taschini (2008). And also their Kurtoses are larger than three and skewnesses are less than zero, indicating their salient leptokurtosis and fat-tailedness. Furthermore, it can be found that the extent of leptokurtosis and fat-tailedness appears more evident in Phase I than that in Phase II. This is mainly because the carbon market in Phase I of the EU ETS is defined as the pilot phase, various unexpected events 
may significantly affect the sharp changes of carbon price (Zhang and Wei, 2010a).

Table 1 Summary statistics for price returns of carbon futures contract DEC07 and DEC10

\begin{tabular}{ccccccccc}
\hline Return & Obs. & Mean & $\begin{array}{c}\text { Std. } \\
\text { Dev. }\end{array}$ & Max & Min & Skewness & Kurtosis & JB test \\
\hline DEC07 & 681 & -1.0918 & 10.7281 & -138.6294 & 109.8612 & -3.1738 & 75.9231 & 152035.2 \\
& & & & & & & & $(0.0000)$ \\
DEC10 & 753 & -0.0724 & 2.7430 & 10.8794 & -12.2002 & -0.3264 & 5.4008 & 194.2189 \\
& & & & & & & & $(0.0000)$ \\
\hline
\end{tabular}

Note: $P$-values for corresponding null hypotheses are reported in parentheses.

\subsection{Empirical results based on the EVT-VaR approach}

Due to the shortcomings of traditional VaR approaches (such as Variance-Covariance, Monte Carlo) to estimate the extreme risk of tail distribution, we introduce the EVT to measure the VaR of carbon futures market of the EU ETS. It should be noted that according to Fernandez (2005), in theory, the conditional EVT often may produce better results than the unconditional EVT because the former can filter out heteroskedasticity and serial correlation by multivariate GARCH models. We estimate the VaRs based on conditional and unconditional EVT respectively, and find that both the results based on conditional and unconditional EVT are reliable at 95\% level according to the LR statistic by Kupiec (1995), and their LR values are fairly close. Therefore, for the sake of simplicity, we choose the unconditional EVT in the paper. ${ }^{1}$

In the model, we consider both the upside and downside VaRs, in which the carbon price return series is used for upside VaR and the loss (minus return) series for downside VaR. Taking the downside VaR of contract DEC07 as an example, we would like to briefly show the calculating procedure.

First, the threshold value $u$ is estimated. Based on the loss series of contract DEC07, the mean excess function (MEF) plot is obtained as Figure 2. As can be seen from the figure, e $(u)$ appears approximately linear when $R>6.9$, therefore, here we select the threshold value $u=6.9$. Then we estimate the parameters $\xi$ and $\beta$, and the results of Maximum Likelihood Estimation (MLE) based on Eq. (4) show that $\xi=0.4272$ and $\beta=5.6635$.

\footnotetext{
1 The detailed results based on the conditional EVT can be obtained upon request.
} 


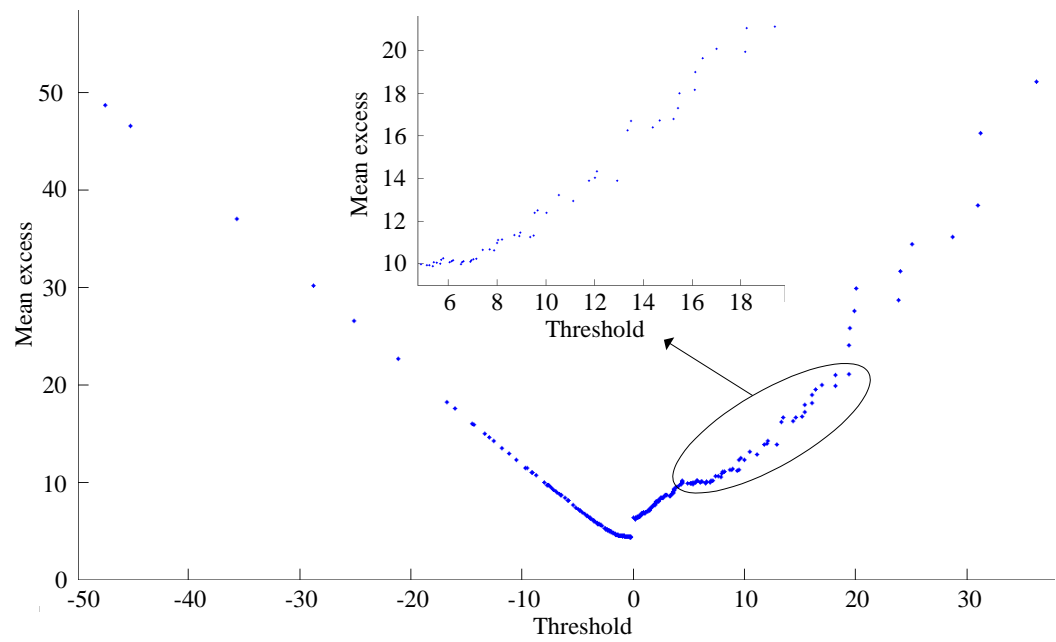

Fig. 2. The mean excess function (MEF) plot of loss series of carbon contract DEC07

Subsequently, according to Eq. (8), we estimate the VaRs of carbon futures prices of the two phases and results are reported in Table 2. From the results in Table 2, several findings can be identified.

Table 2 The VaR estimation results for contract DEC07 and DEC10

\begin{tabular}{cccccccccc}
\hline & & $u$ & $\xi$ & $\beta$ & VaR & $n$ & $N$ & $f$ & LR \\
\hline \multirow{2}{*}{ DEC07 } & Downside & 6.9 & 0.4272 & 5.6635 & 12.7383 & 681 & 36 & 0.0529 & 0.1155 \\
& Upside & 3.8 & 0.4370 & 4.2741 & 7.5038 & 681 & 35 & 0.0514 & 0.0277 \\
\multirow{2}{*}{ DEC10 } & Downside & 2.2 & 0.1439 & 1.7033 & 4.4310 & 753 & 37 & 0.0491 & 0.0119 \\
& Upside & 3.4 & 0.0804 & 1.4451 & 4.2298 & 753 & 38 & 0.0505 & 0.0034 \\
\hline
\end{tabular}

Note: The results in the table are based on the confidence level of $95 \%$. And the detailed results at $99 \%$ level can be obtained upon request.

First, it can be seen that all the LR values are less than the critical value 3.84, which means the null hypotheses may be accepted. In other words, we may say that both the downside and upside VaRs for contract DEC07 and DEC10 based on the EVT approach are statistically reliable during the sample period. This result is closely related with the economic background of EUA. As detailed in previous literature (Zhang and Wei, 2010a), we may distinguish between factors determining the supply and demand of EUAs when the drivers of EUAs price are discussed. The supply of EUAs is fixed by the European Commission in National Allocation Plans that are validated after negotiation between Member States and national industrials covered by the EU ETS. And announcements relative to the strictness of NAPs have been shown to have a strong influence on EUA prices (Chevallier et al., 2009). Concerning demand factors, previous literature identifies energy prices, weather events and the level of industrial production as being the main 
drivers of EUAs during Phase I (Mansanet-Bataller et al., 2007), in Phase II, those factors also play an important role in EUAs price fluctuation (Mansanet-Bataller et al., 2011). Due to the complex movements of various drivers, the prices of EUAs change in a volatile way, which produces sharp extreme risks and needs appropriate methods to reliably estimate the risks.

Second, the average of downside VaRs outweighs that of upside VaRs for the two carbon futures contracts. Particularly for contract DEC07 in Phase I, the average downside VaR proves 1.7 times larger than the upside VaR. This evidence is closely related with the market conditions in Phase I. In the proposal of the EU ETS, the surplus allowances cannot be banked or borrowed between Phase I and Phase II, which results in a salient seam between them. Plus the over-allocation of emissions allowance in Phase I, the downside price trends basically dominate the carbon trading markets in Phase I especially in its late period. Even at the end of 2007, the carbon price approached zero. It should also be noted that the asymmetric effect of VaRs for downside and upside market conditions is sharply reduced in Phase II compared with that in Phase I; specifically the ratio of downside VaR to upside VaR declines from 1.7 to 1.05 , which implies the increasingly improved market environment for carbon futures trading under the EU ETS.

Finally, whether for the downside or upside extreme market risks, the risk extent in Phase II appears less than that of Phase I respectively, which to some extent reflects that the promising future of carbon market has been gradually accepted by investors concerned; as a result, carbon price maintains a relatively stable trend in Phase II.

\subsection{Comparison of VaR results based on different approaches}

In order to compare the difference of VaRs using EVT and traditional approaches, we employ the traditional Variance-Covariance and Monte Carlo approaches and recalculate the VaRs of carbon futures prices in the two phases. It should be noted that the Variance-Covariance approach is based on the GED-GARCH models. Results are reported in Table 3.

We find that whether for contract DEC07 or DEC10, the LR statistic values based on EVT approach appear less than those based on the traditional approaches except for the DEC10 upside (the LR value based on the Variance-Covariance equals that based on the EVT). As for the contract DEC07, the exceedance rates $(f)$ based on the traditional approaches are much less than 5\% while LR values larger by far than 3.84 , which implies that the estimation by the two 
traditional approaches are biased and cannot be considered to be the basis of decision making for investors. It should be noted that the Monte Carlo approach over-estimates all the VaRs of carbon futures market.

Table 3 Comparison of the VaR estimation results based on three different approaches

\begin{tabular}{cccccccc}
\hline \multirow{6}{*}{ DEC07 } & & VaR & $n$ & $N$ & $f$ & LR \\
\hline \multirow{3}{*}{ Downside } & EVT & 12.7383 & 681 & 36 & $5.29 \%$ & 0.1155 \\
& & VC & 10.3469 & 681 & 49 & $7.20 \%$ & 6.1192 \\
& \multirow{2}{*}{ Upside } & MC & 20.6997 & 681 & 11 & $1.62 \%$ & 22.0531 \\
& & EVT & 7.5038 & 681 & 35 & $5.14 \%$ & 0.0277 \\
& & VC & 9.7555 & 681 & 20 & $2.94 \%$ & 7.1190 \\
& & MC & 16.0291 & 681 & 9 & $1.32 \%$ & 27.1068 \\
& Downside & EVT & 4.4310 & 753 & 37 & $4.91 \%$ & 0.0119 \\
& & VC & 4.2143 & 753 & 46 & $6.11 \%$ & 1.8262 \\
& & MC & 4.9056 & 753 & 29 & $3.85 \%$ & 2.2640 \\
& \multirow{2}{*}{ Upside } & EVT & 4.2298 & 753 & 38 & $5.05 \%$ & 0.0034 \\
& & VC & 4.2199 & 753 & 38 & $5.05 \%$ & 0.0034 \\
\hline
\end{tabular}

Note: The results in the table are based on the confidence level of $95 \%$. The results at $99 \%$ level have similar implications and the detailed results can be obtained upon request. EVT, VC and MC denote the Extreme Value Theory, Variance-Covariance and Monte Carlo approaches respectively.

In addition, the LR values of the two traditional approaches in Phase II are less than 3.84, both for the downside and upside risks, which means the VaR estimation using the traditional approaches for Phase II here is supposed to be acceptable at the confidence level of $95 \%$ during the sample period. Even so, it should be noted that whether for the downside or upside risks, the estimation based on the EVT approach proves much more reliable for its relatively least LR values.

To sum up the VaR estimation results in Phase I and Phase II, it can be found that the more volatile carbon market appears, the more reliable and advantageous the EVT approach may prove compared with the traditional approaches.

\section{Conclusions and implications}

In light of the sharp volatility in EU ETS carbon futures markets, this paper introduces the Extreme Value Theory (EVT) to empirically study the extreme risk of carbon prices in both Phase I and Phase II. And some main conclusions and implications are obtained. 
First, the EVT approach can be used to reliably measure the extreme risk (VaR) of carbon futures markets of the EU ETS, both for Phase I and Phase II. This mainly results from the fact that carbon market acts as an emerging market and still faces a number of immature mechanisms. Particularly in the first phase of the EU ETS, due to the weak market capacity and low market liquidity, the carbon price dynamic is easy to be influenced by international political conditions (such as the climate negotiation dynamics), energy price changes, unusual temperature and emissions allowance allocation solution disclosure etc.; as a result, carbon price has experienced a salient volatility.

Second, the downside extreme risk of carbon futures market outweighs the upside risk, with evident asymmetric features in the sample period. In other words, the risk faced by carbon emissions allowance sellers is larger than that of buyers. Specifically, the downside extreme risk of contract DEC07 in Phase I proves 1.7 times larger than that of upside risk, which is mainly ascribed to the immature market mechanism especially the over-allocation allowance and the seam between the two phases. In Phase II, the asymmetric effect of risk has been reduced sharply, the ratio of downside $\mathrm{VaR}$ to upside $\mathrm{VaR}$ declines from 1.7 to 1.05 , which implies the increasingly improved market environment for carbon trading.

Moreover, the average of VaR of carbon futures contract DEC10 proves much less than that of contract DEC07 in the sample period. Specifically, the average downside and upside VaRs of contract DEC07 are 12.74 and 7.50 in the sample period, but those for contract DEC10 are 4.43 and 4.23 respectively. This switch re-validates the increasingly improved market trading mechanisms of the EU ETS and also is conducive to attract more investors to participate in the carbon trading; as a result, carbon trading market may help reduce carbon emissions in a cost-effective way.

\section{Acknowledgements}

We gratefully acknowledge the financial support from the National Natural Science Foundation of China (nos. 71001008, 70733005, 71020107026), Humanities and Social Science Research Foundation of Ministry of Education of China (no. 09YJC630011), Specialized Research Fund for the Doctoral Program of Higher Education (no. 20101101120041), Excellent Young Scholars Research Fund of Beijing Institute of Technology (no. 2010Y1317) and Excellent 
Talent Research Fund of Beijing Municipality (no. 2011D009011000008). We also would like to express our sincere gratitude to Prof. Julien Chevallier for the guidance and encouragement.

\section{References}

Alberola, E., Chevallier, J. (2009) 'European carbon prices and banking restrictions : Evidence from Phase I (2005-2007)', The Energy Journal, Vol. 30, pp.51-80.

Alberola, E., Chevallier, J., Cheze, B. (2008a) 'The EU Emissions Trading Scheme: the effects of industrial production and $\mathrm{CO}_{2}$ emissions on European carbon prices', Int Econ, Vol. 116, pp.95-128.

Alberola, E., Chevallier, J., Chèze, B. (2008b) 'Price drivers and structural breaks in European carbon prices 2005-2007', Energy Policy, Vol. 36, pp.787-797.

Balkema, A.A., Haan, L.d. (1974) 'Residual lifetime at great age', Annals of Probability, Vol. 2, pp.792-804.

Blanco, M.I., Rodrigues, G. (2008) 'Can the future EU ETS support wind energy investments?', Energy Policy, Vol. 36, pp.1509-1520.

Blyth, W., Bunn, D. (2011) 'Coevolution of policy, market and technical price risks in the EU ETS', Energy Policy, Vol. 39, pp.4578-4593.

Blyth, W., Bunn, D., Kettunen, J., Wilson, T. (2009) 'Policy interactions, risk and price formation in carbon markets', Energy Policy, Vol. 37, pp.5192-5207.

Chevallier, J. (2009) 'Carbon futures and macroeconomic risk factors: A view from the EU ETS', Energy Economics, Vol. 31, pp.614-625.

Chevallier, J., Ielpo, F., Mercier, L. (2009) 'Risk aversion and institutional information disclosure on the European carbon market: A case-study of the 2006 compliance event', Energy Policy, Vol.37, pp.15-28.

Daníelsson, J., de Vries, C.G. (1997) 'Tail index and quantile estimation with very high frequency data', Journal of Empirical Finance, Vol. 4, pp.241-257.

Daskalakis, G., Markellos, R.N. (2009) 'Are electricity risk premia affected by emission allowance prices? Evidence from the EEX, Nord Pool and Powernext', Energy Policy, Vol. 37, pp.2594-2604. 
Fan, Y., Zhang, Y.-J., Tsai, H.-T., Wei, Y.-M. (2008) 'Estimating 'Value at Risk' of crude oil price and its spillover effect using the GED-GARCH approach', Energy Economics, Vol. 30, pp.3156-3171.

Feng, Z.-H., Zou, L.-L., Wei, Y.-M. (2011) 'Carbon price volatility: Evidence from EU ETS', Applied Energy, Vol. 88, pp.590-598.

Fernandez, V. (2005) 'Risk management under extreme events', International Review of Financial Analysis, Vol. 14, pp.113-148.

Gilli, M., Kellezi, K. (2006) 'An application of extreme value theory for measuring financial risk', Computational Economics, Vol. 27, pp.207-228.

Katz, R.W., Parlange, M.B., Naveau, P. (2002) ‘Statistics of extremes in hydrology’, Advances in Water Resources, Vol. 25, pp.1287-1304.

Kupiec, P.H. (1995) 'Techniques for verifying the accuracy of risk measurement models', Journal of Derivatives, Vol. 3, pp.73-84.

Linacre, N., Kossoy, A., Ambrosi, P. (2011) State and Trends of the Carbon Market 2011, Washington, DC: World Bank.

Longin, F.M. (2000) 'From value at risk to stress testing: the extreme value approach', Journal of Banking \& Finance, Vol. 24, pp.1097-1130.

Mansanet-Bataller, M., Pardo, A., Valor, E. (2007) ' $\mathrm{CO}_{2}$ price, energy and weather', The Energy Journal, Vol. 28, pp. 67-86.

Mansanet-Bataller, M., Chevallier, J., Herve-Mignucci, M., Alberola, E. (2011) 'EUA and sCER phase II price drivers: unveiling the reasons for the existence of the EUA-sCER spread', Energy Policy, Vol. 39, pp.1056-1069.

Marimoutou, V., Raggad, B., Trabelsi, A. (2009) 'Extreme Value Theory and Value at Risk: Application to oil market', Energy Economics, Vol. 31, pp.519-530.

McNeil, A.J. (1997) 'Estimating the tails of loss severity distributions using extreme value theory', Astin Bulletin, Vol. 27, pp.117-137.

Oberndorfer, U. (2009) 'EU Emission Allowances and the stock market: Evidence from the electricity industry', Ecological Economics, Vol. 68, pp.1116-1126.

Paolella, M.S., Taschini, L. (2008) ‘An econometric analysis of emission allowance prices’, Journal of Banking \& Finance, Vol. 32, pp.2022-2032.

Pickands, J. (1975) 'Statistical inference using extreme order statistics', Annals of Statistics, Vol. 3, 
pp.119-131.

Pinho, C., Madaleno, M. (2011) 'CO2 emission allowances and other fuel markets interaction', Environmental Economics and Policy Studies, Vol. 13, pp.259-281.

Reilly, J., Paltsev, S. (2007) 'An analysis of the European emission trading scheme', http://web.mit.edu/globalchange/www/MITJPSPGC_Rpt127.pdf.

Wei, Y.-M., Wang, K., Feng, Z.-H., Cong, R.-G. (2010) Carbon finance and carbon market: models and empirical analysis [in Chinese], Beijing: Science Press.

Zhang, Y.-J., Wei, Y.-M. (2010a) 'An overview of current research on EU ETS: Evidence from its operating mechanism and economic effect', Applied Energy, Vol. 87, pp.1804-1814.

Zhang, Y.-J., Wei, Y.-M. (2010b) 'Interpreting the complex impact of fossil fuel markets on the EU ETS futures markets: An empirical evidence' [in Chinese], Management Review, Vol. 22, pp.34-41.

Zhang, Y.-J., Wei, Y.-M. (2011) 'Interpreting the mean reversion of international carbon futures price: Empirical evidence from EU ETS' [in Chinese], Systems Engineering - Theory \& Practice, Vol.31, pp.214-220. 